\title{
Avaliação da capacidade funcional do paciente pós-trauma
}

\author{
Evaluation of the functional capacity \\ of the post-Trauma patient
}

FisiSenectus . Unochapecó Ano 7, n. 1 - Jan/Jun. 2019 p. 3-14

\begin{abstract}
Liliana Gama Oliveira. lilihannag@hotmail.com
Fisioterapeuta pela Universidade de Fortaleza (Unifor). Pós-graduanda em Fisioterapia Respiratória Cardiovascular Ambulatorial e em UTI na Unifor.
\end{abstract}

Cleidiane Gonzaga Damasceno de Souza. cleidiane.gonzaga28@yahoo.com.br

Fisioterapeuta pela Universidade de Fortaleza (Unifor). Bolsista do Programa Aluno Voluntário de Iniciação Cientifica da Fundação Edson Queiroz (Probic/Fortaleza-CE).

Jocasta Porfirio de Souza. jocastaporfirio@hotmail.com

Fisioterapeuta pela Univerdade de Fortaleza (Unifor). Bolsista do Programa de Iniciação

Cientifica da Fundação Edson Queiroz (Pavic/Fortaleza-CE). Pós-graduanda em Gerontologia na Unifor.

Margylly Hyanne Cardoso de Araújo. margylly.cardoso@gmail.com

Fisioterapeuta pela Univerdade de Fortaleza (Unifor). Bolsista do Programa Institucional bolsas de Iniciação Científica (Pibic/Fortaleza-CE).

José Nilson Rodrigues de Menezes. nilson.pesquisa@hotmail.com

Fisioterapeuta pela Universidade de Fortaleza (Unifor). Doutor em Biotecnologia pela Universidade Estadual do Ceará (Uece-Renorbio). Professor na Unifor no Curso de Fisioterapia e Psicologia e na Pós-Graduação de Neurociência Reabilitação no Centro de Ciência da Saúde (CCS-Fisioterapia).

\section{Resumo}

Introdução: o trauma é um agravo à saúde, definido como um acontecimento nocivo caracterizado por alterações estruturais ou pelo desequilíbrio fisiológico do organismo resultante da troca de energia entre os tecidos e o meio. Objetivo: avaliar a capacidade funcional do indivíduo pós-trauma. Métodos: pesquisa quantitativa, do tipo descritivo. Realizada no Núcleo de Atenção Médica Integrada, com indivíduos pós-trauma atendidos no Serviço de Fisioterapia, nos meses de outubro a dezembro de 2017. Foram incluídas pessoas do sexo masculino e do feminino a partir de 18 anos de idade, e foram excluídos indivíduos com dificuldades na fala ou alterações no estado mental que inviabilizasse a entrevista. Os dados foram coletados por meio da escala de Medida de Independência Funcional (MIF) e um questionário sociodemográfico, a amostra foi constituída por 26 participantes. Resultados: a amostra consistiu em 26 indivíduos (n=26), que vinham sendo atendidos pelo setor de fisioterapia, tendo como conduta terapêutica: terapias manuais e eletroterapia, com o objetivo de recuperar a dor e a funcionalidade desses indivíduos, a faixa etária de foi de 18 a 70 anos com média de idade $42,92 \pm 16,35$, havendo uma prevalência do sexo masculino. Dos indivíduos deste estudo, 77\% apresentaram uma independência completa, 8\% necessitavam de assistência em até 50\% das tarefas,

\section{Fisiß̌enectus}


11\% necessitam de assistência em até 25\% das tarefas e 4\% tinha dependência completa. Considerações finais: foi possível concluir que a maioria dos pacientes pós-trauma que frequentaram a instituição, por mais que tenham alguma alteração física ou cognitiva, apresentaram uma boa capacidade funcional, sendo funcionalmente independentes e capazes de realizar as atividades cotidianas, com o mínimo de ajuda possível.

\title{
Palavras-chave
}

Funcionalidade; Fisioterapia; Trauma.

\begin{abstract}
Introduction: Trauma is a health problem, defined as a harmful event characterized by structural alterations or by the physiological imbalance of the organism resulting from the exchange of energy between the tissues and the medium. Objective: To evaluate the functional capacity of the individual after trauma. Methods: Quantitative research, descriptive type. It happened at the center of Integrated Medical care, with post-trauma individuals attended at the physiotherapy service, in the months of October to December of 2017. Male and female subjects were included from 18 years of age, and individuals with speech difficulties or alterations in the mental state that prevented the interview were excluded. Data were collected through the functional independence measure scale and a sociodemographic questionnaire, the sample consisted of 26 participants. Results: The sample consisted of 26 individuals $(n=26)$, who were attended by the physiotherapy sector, having as therapeutic conduct: manual therapies and electrotherapy, with the objective of recovering the pain and functionality of these individuals, the age range was 18 to 70 years old with mean age $42.92 \pm 16.35$, with a male prevalence. The individuals in this study $77 \%$ had complete independence, $8 \%$ needed assistance of up to $50 \%$ of the tasks, $11 \%$ need assistance of up to $25 \%$ of the tasks and $4 \%$ of complete dependence. Final considerations: It was possible to conclude that the majority of post-trauma patients who attended the institution, as much as they had some physical or cognitive alteration, had a good functional capacity, being functionally independent and Capable of performing daily activities, with the least possible help.
\end{abstract}

\section{Keywords}

Functionality; Physiotherapy; Trauma.

\section{Introdução}

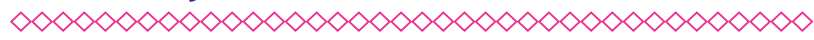

O trauma é um agravo à saúde, definido como um acontecimento nocivo caracterizado por alterações estruturais ou pelo desequilíbrio fisiológico do organismo resultante da troca de energia entre os tecidos e o meio. É considerada uma morbidade que compromete a funcionalidade do indivíduo e sua participação social e econômica na socieda$\mathrm{de}^{1}$. Podendo levar ao indivíduo consequências, econômicas e sociais. Os traumatismos são responsáveis por causar invalidez prolongada ou até mesmo permanente ${ }^{2}$.

Podem acontecer de forma penetrante, ocasionados por armas de fogo, armas brancas e quedas. No trauma fechado o osso sofre uma força de torção, devido a acidentes automobilísticos e quedas $^{3}$. 0 traumatismo crânio encefálico (TCE) é um trauma que acomete o couro cabeludo, crânio e encéfalo depois de lesões fechadas ou penetrantes, dentre elas estão a contusão, a fratura de crânio, a hematoma epidural ou subdural ${ }^{4}$. 0 trauma raquimedular (TRM) é uma lesão medular devido à fratura da coluna vertebral que provoca alterações motoras, autonômicas, sensitivas. Relacionada à queda da própria altura, mergulhos em águas rasas, e acidentes automobilísticos ${ }^{5}$.

Os motociclistas representam o grupo mais vulnerável a múltiplos traumas de maior gravidade por exposição direta ao impacto. Portanto, as motocicletas são consideradas uma das formas mais perigosas de transporte, devido ao pequeno tamanho dos veículos. Os acidentes envolvendo motociclistas tornaram-se uma questão de saúde pública importante, especialmente os fatais ${ }^{6}$.

As contusões musculares são lesões decorrentes de traumas sobre um grupo muscular devido a um contato físico, por ser um trauma fechado, tanto a pele quanto a musculatura poderão sofrer 
graus variados de lesões ${ }^{7}$. As lesões musculares são mais comuns, geralmente afetam músculos superficiais e biarticulares. Fatores de risco, como lesão muscular pregressa da mesma região, idade, sobrecarga, alteração na força e capacidade de alongamento dos músculos ${ }^{8}$.

As fraturas são apontadas como uma quebra estrutural do osso em sua continuidade podendo ser fechada ou aberta. São classificadas em galho verde, cominutiva, transversa, oblíqua e a espiralada ${ }^{9}$. As fraturas patológicas que ocorrem de maneira espontânea sobre o osso fragilizado são mais comuns em idosos devido à osteoporose. Ocorre sem grandes forças aplicadas no local lesionado no osso, ou seja, pouquíssima força já pode ocasionar a fratura no osso ${ }^{10}$. Portanto, entender de fraturas é de suma importância para o tratamento, pois indica uma melhor orientação quanto ao plano de tratamento e o prognóstico ${ }^{11}$.

As implicações decorrentes do trauma ortopédico englobam, além de questões relacionadas ao bem-estar físico do indivíduo, aspectos socioeconômicos em decorrência das incapacidades temporárias ou permanentes ${ }^{12}$. Com isso as consequências econômicas e sociais do trauma são de alta proporção, devido ao elevado custo da recuperação e gastos da Previdência Social ${ }^{13}$.

Portanto, a saúde funcional, além de ser indicador do estado de saúde, é ótimo indicador de revisão dos custos e recursos dos cuidados de saúde. A funcionalidade e a incapacidade de um indivíduo são desenvolvidas como uma interação dinâmica entre os estados de saúde (lesões, doenças, traumas) e os fatores contextuais ${ }^{14}$.

Desse modo, o presente estudo teve como objetivo avaliar a capacidade funcional do indivíduo pós-trauma.

\section{Métodos}

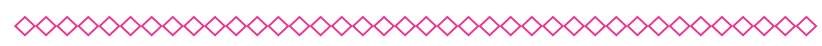

Foi realizado um estudo descritivo de natureza quantitativa nos meses de outubro a dezembro de 2017, com indivíduos pós-trauma que frequentaram o Setor de Fisioterapia do Núcleo de Atenção Médica Integrada (NAMI), localizado na rua
Desembargador Floriano Benevides, 221, bairro Edson Queiroz, Fortaleza-CE. A amostra foi constituída de 26 participantes sendo incluídos pacientes do sexo masculino e do feminino a partir de 18 anos de idade, que já realizavam atendimento fisioterapêutico regularmente, com no mínimo cinco atendimentos, e que possuíssem disfunções pós-trauma. Foram excluídos pacientes com dificuldades na fala ou alterações no estado mental que inviabilizasse 0 preenchimento do questionário.

A forma de recrutamento dos participantes foi por chamada pública na forma de palestra na qual foi explicado aos pacientes os objetivos e métodos da pesquisa; posteriormente, os pacientes foram convidados a participar do estudo e os que tiveram interesse em participar assinaram o Termo de Consentimento Livre e Esclarecido.

Os dados foram coletados por meio da Escala de Medida de Independência Funcional (MIF) ${ }^{15}$. Essa escala é um instrumento que avalia o grau de independência funcional identificando o grau de dificuldade e suas limitações ${ }^{16}$, é uma ferramenta multidimensional com o objetivo de avaliar o paciente em vários aspectos, como os sociais, o motor e o cognitivo, especificado no deambular, vestir, comer, higienizar, resolver problemas, expressar, inteirar-se socialmente, compreender e memorizar. Cada tópico é pontuado de 1 a 7, e a somatória dos 18 itens varia de 18 a 126 pontos, e a maior pontuação significa uma completa independência funcional ${ }^{17}$. Também foi aplicado um questionário sociodemográfico, com questões, como: sexo, idade, profissão, tipos de trauma com as opções de respostas: traumatismo craniano, traumatismo raquimedular, fraturas e outros; e causas da lesão com as opções de resposta: queda, mergulho, violência urbana, acidente automobilístico, acidente motociclístico e outros. Os dados foram analisados por meio do programa Microsoft Office Excel 2007 e dispostos em gráficos.

A pesquisa respeitou os aspectos éticos, de acordo com as Diretrizes e Normas de Pesquisa em Seres Humanos constante na Resolução n 466 , de 12 de dezembro de 2012, do Conselho Nacional de Saúde ${ }^{18}$ e foi aprovado pelo Comitê de Ética em Pesquisa da Universidade de Fortaleza, com Parecer $n^{0} 2.234 .840$. 


\section{Resultados}

$\diamond<\infty<\infty<\infty<\infty<\infty<\infty<\infty<\infty<\infty<\infty<\infty<\infty<\infty<\infty<\infty<$

A amostra consistiu em 26 indivíduos ( $n=26)$, que vinham sendo atendidos pelo Setor de Fisioterapia, tendo como conduta terapêutica: terapias manuais e eletroterapia, com o objetivo de diminuir a dor e melhorar a funcionalidade desses indivíduos, cuja faixa etária era de 18 a 70 anos com média de idade $42,92 \pm 16,35$, havendo a prevalência do sexo masculino (73\%:n=19). As causas dos traumas foram acidentes automobilísticos (31\%: $n=8)$, quedas ( $31 \%: n=8)$, violência urbana (19\%:n=5), acidente motociclístico (15\%:n=4), mergulho $(4 \%: n=1)$, vítima de fratura $(62 \%: n=16)$, TRM $(19 \%: n=5)$ e outros com $(19 \%: n=5)$.

As características concernentes às categorias da MIF: autocuidado, mobilidade, transferência e locomoção apresentaram uma porcentagem superior a $77 \%$ alcançando o máximo em $88 \%$ demonstrando independência completa. Quanto às subcategorias, como vestir inferior e transferência de banheira para chuveiro apresentou $73 \%$, e transferência para vaso sanitário com $69 \%$ para independência completa, sendo que para as subcategorias marcha/cadeira $50 \%$ e escada é $46 \%$ (Figuras 1, 3 e 4).

Quanto ao domínio dos esfíncteres, referente ao controle da urina e das fezes, mostrou uma prevalência para independência completa, com valores de $76 \%$, o que corresponde aos pacientes que apresentavam autonomia e controle da urina e fezes, sendo que $8 \%$ necessitam de ajuda total relacionados aos controles de urina e $8 \%$ para 0 controle de fezes. Essa menor percentagem se refere aos pacientes vítimas de TRM que utilizavam fraldas geriátricas, devido ao pouco controle das suas necessidades fisiológicas (Figura 2).

Esses resultados mostram de maneira significativa que a maioria dos pacientes foi capaz de compreender e se expressar de forma clara e objetiva, entendendo os comandos e diálogos verbais; em relação à função cognitiva, comunicação e cognição social, os resultados mostraram que $96 \%$ dos pacientes apresentaram ter uma independência completa em todas as subcategorias, sendo que apenas $4 \%$ necessitam de ajuda total nos aspectos interação social, resolução de problemas e memória, enquanto que para a compreensão existem em $4 \%$ que apresentaram independência modificada e 4\% de ajuda mínima para expressão (Figura 4).

Os resultados foram obtidos pelo os escores da MIF contendo 18 itens, agrupados em seis dimensões: autocuidado, locomoção, transferência, comunicação, controle dos esfíncteres e cognição social. Cada item pode receber pontuação de 1 a 7 , correspondendo, respectivamente, à dependência total e à independência completa. Cada aspecto é analisado pela soma dos itens que a compõem. 0 escore total da MIF é dado pela somatória dos escores de cada dimensão e pode variar de 18 a 126 pontos. Os níveis de dependência são classificados de acordo com os escores total da MIF: 18 dependência completa; 19 a 60 dependência modificada (assistência de até $50 \%$ das tarefas); 61 a 103: dependência modificada (assistência de até $25 \%$ das tarefas); e 104 a 126: independência completa/modificada ${ }^{19}$.

Analisando os resultados, pode-se observar que $77 \%$ dos pacientes deste estudo mostraram ter uma independência completa, 8\% necessitavam de assistência em até $50 \%$ das tarefas, $11 \%$ necessitam de assistência em até $25 \%$ das tarefas e $4 \%$ apresentaram dependência completa (Figura 5).

\section{Discussão}

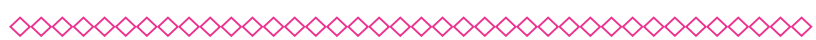

O estudo de Ascari, Chapieski, Silva e Frigo 20 realizado com pacientes vítimas de traumas apresentou um maior percentual de pessoas que sofreram acidentes automobilísticos, representadas por $69 \%$, sendo a maior causa de trauma em relação a outros tipos de acidentes. Estando em concordância com os resultados apresentados neste estudo.

Em relação ao mecanismo do trauma, o estudo de Carvalho e Saraiva ${ }^{21}$ mostrou que a queda é um dos fatores principais da causa de trauma, estando acima dos provocados por armas de fogo. Os resultados presentes neste estudo mostraram que o fator queda teve uma porcentagem semelhante aos acidentes automobilísticos sendo os mecanismos de traumas mais comuns. 
A pesquisa de Credo e Felix ${ }^{22}$ evidenciou que indivíduos do sexo masculino são os mais acometidos por algum tipo de trauma. Esse estudo corrobora com os resultados analisados nesta pesquisa, a qual apresentou uma predominância de indivíduos do sexo masculino que sofreram algum tipo de acidente e em consequência determinados traumas.

Em relação às categorias da MIF em um estudo sobre a independência funcional em pacientes após alta da Unidade de Terapia Intensiva realizado por Curze, Junior e Rieder ${ }^{23}$ demonstrou um menor prejuízo relacionado à categoria do autocuidado. Estando em concordância com este estudo, no qual os indivíduos não apresentaram prejuízos significativos, mostrando que houve um menor comprometimento nesses indivíduos relacionado à categoria autocuidado.

Alguns achados demonstram que os resultados das categorias transferências, locomoção, cognição social revelaram uma diminuição da assistência durante as atividades de vida diária, o que significa uma independência completa apresentada pela maior parte dos pacientes ${ }^{24}$. Esse achado é similar aos resultados deste estudo, pois aponta uma prevalência na autonomia para executar determinadas atividades de vida diária.

Foram identificados por Vasconcelos ${ }^{25}$ que a maioria dos pacientes apresentou uma independência completa com relação à categoria cognitiva em suas respectivas subcategorias. Isso corrobora com esta pesquisa, pois houve uma semelhança nos resultados apresentados, que demonstraram de maneira significativa que os indivíduos são capazes de se expressarem e compreenderem de forma clara e objetiva, não demonstrando danos na função cognitiva.

A avaliação por intermédio da MIF é indispensável para qualquer profissional da saúde, principalmente para o fisioterapeuta. Com ela, pode-se avaliar a capacidade funcional motora e cognitiva, bem como analisar as limitações e necessidades pontuadas com o propósito de facilitar a escolha do melhor tipo de monitorização e intervenção do estado clínico-funcional do indivíduo, tornando-o mais independente para realizar as atividades de vida diária (AVDs) ${ }^{26}$.
Compreende-se como avaliação funcional a designação dada para uma atividade específica, a capacidade de realizar atividade do autocuidado e atender suas necessidades básicas diárias, ou seja, as AVDs. A MIF tem como objetivo mensurar a capacidade funcional e independência do paciente estimando o grau de dificuldade ou limitações atribuídas a cada pessoa ${ }^{27}$. É uma escala que se baseia em elementos necessários para a avaliação da independência funcional proporcionando resultados por meio de seu escore total. Tornando-se um instrumento frequentemente utilizado para avaliar as atividades motoras e cognitivas.

No contexto geral, os resultados demonstraram que, em todas as categorias, encontra-se um maior porcentual para independência completa, isso mostra que a maioria dos indivíduos consegue realizar suas atividades com autonomia, diferentemente da sub categoria que é correspondente à locomoção: marcha, transferência para cadeira e subir/descer escadas, indicando que a metade deles necessita de auxílio para executá-las.

As sequelas do trauma estão entre as patologias crônicas de longa duração que ocasiona deficiências e levam a limitações na prática de atividades diárias, como também à restrição de desempenho de papéis sociais dos indivíduos ${ }^{28}$. No presente estudo, os resultados apresentados encontram-se semelhantes, pois mostram que as consequências decorrentes do trauma envolvem questões relacionadas ao bem-estar físico do indivíduo, quanto à dificuldade de executar simples atividades diárias.

0 trauma físico vem a provocar limitações físicas, psicológica e mudanças nos pacientes vítimas de traumas, pois ocasiona nesses indivíduos uma incapacidade para retomar as AVDs de modo permanente ou parcial. ${ }^{29}$ Baseando-se nesse estudo, observou-se que há uma concordância nos resultados, pois mostrou que o trauma físico pode vir a acarretar mudanças e limitações no paciente em relação ao seu trabalho e suas AVDs.

Em termos práticos tais implicações referem-se às restrições e exceções para exercer as AVDs, gerando a perda da autonomia e o afastamento do trabalho por vezes definitivo. ${ }^{30}$

No entanto, nas últimas décadas, vem-se observando o aumento crescente do número de 
acidentes envolvendo motocicletas e veículos ${ }^{31}$. 0 avanço no número de acidentes de trânsito representa expressivamente, um grande impacto na economia mundial, não só pelos altos custos com atendimento e internação das vítimas, mas também por ser responsável pela morte significativa de uma parcela da população economicamente ativa, uma vez que o perfil das vítimas fatais tem sido predominantemente de pessoas do sexo masculino e de faixa etária adulta produtiva ${ }^{32}$. Os dados obtidos no presente estudo só confirmam as atuais estatísticas de acidentes de trânsito.

Nota-se que este estudo apresenta limitações, por ter sido executado em uma única instituição de referência a assistência fisioterapêutica, portanto, necessita de mais evidências científicas.

\section{Considerações finais}

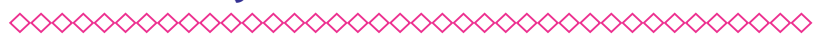

Neste estudo, foi possível concluir que a maioria dos pacientes pós-trauma que frequentaram a instituição, por mais que tenham alguma alteração física ou cognitiva, apresentaram boa capacidade funcional, sendo independentes e capazes de realizar as AVDs, com o mínimo de ajuda possível.

\section{Referências}

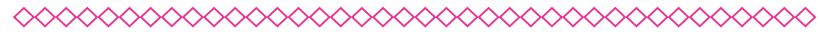

1. Santos LFS, Fonseca JMA da, Cavalcante BLS, Lima CM. Estudo epidemiológico do trauma ortopédico em um serviço público de emergência. Cad saúde colet. 2016;24(4):397-403.

2. Santana VR, Feitosa MFG. Avaliação epidemiológica das vítimas de trauma abdominal submetidas ao tratamento cirúrgico. Rev Col Bras Cir. 2012;39(4):200-9.

3. Grahan A, Solomon L. Ortopedia e fraturas. 6. ed. São Paulo: Atheneu; 2002.

4. Santos F, Casagranda LP, Lange C, Farias JC, Pereira PM, Jardim VMR, et al. Traumatismo cranioencefálico: causas e perfil das vítimas atendidas no pronto-socorro de Pelotas/Rio
5. Grande Do Sul, Brasil. Rev Min Enfermagem. 2013;17(4):882-7.

6. Viúdes MAA, Costa JM, Nunes CMP. Perfil dos pacientes internados por trauma raquimedular em Hospital Público de Ensino. Rev Med. 2015;25(3):380-6.

7. Barros MSA, Furtado BMSM, Bonfim CV. Características clínicas e epidemiológicas de motociclistas com trauma cranioencefálico atendidos em hospital de referência. Rev Enfermagem UERJ. 2015;23(4):540-7.

8. Brukner P, Khan K. Clinical Sports Medicine. 3. ed. Australia: McGraw-Hill; 2006.

9. Opar DA, Williams MD, Shield AJ. Hamstring strain injuries: factors that lead to injury and reinjury. Sports Med. 2012;42(3):209-26.

10. Prentice WE. Fisioterapia na prática esportiva uma abordagem baseada em competências. 14 . ed. Porto Alegre: Artmed; 2012.

11. Brody JT, Hall CM. Exercício terapêutico na busca da função. 3. ed. Rio de Janeiro: Guanabara Koogan; 2012.

12. Moreira BS. A biomecânica da fratura e o processo de cicatrização. Cad Unisuam. 2013;3(1):101-17.

13. Kfuri Júnior M. O trauma ortopédico no Brasil. Rev Bras de Ortop. 2011;46(1):9-12.

14. Silva LAP, Ferreira AC, Paulino RES, Gabriela de OG, Maria EBdaC, Vitória TCPP. et al. Análise retrospectiva da prevalência e do perfil epidemiológico dos pacientes vítimas de trauma em um hospital secundário. Rev Med. 2017 out./ dez;96(4):246-54.

15. Lopes MJ, Escoval A, Pereira DG, Pereira CS, Carvalho C, Fonseca C. Avaliação da funcionalidade e necessidades de cuidados dos idosos. Rev Latino-Am. Enfermagem. 2013;21(1):52-60.

16. Alencar RF, Cordeiro TGF, Anjos PGS, Cavalcanti PL. Facilitação neuromuscular proprioceptiva em tatame na reaquisição de funções na lesão medula. Rev Neurociênc. 2011;19(3):512-8. 
17. Correia DF. Avaliação da capacidade funcional de idosos institucionalizados com demência. [trabalho de conclusão de curso] Fortaleza: Universidade de Fortaleza, Fisioterapia; 2013.

18. Santos TB, Peracini T, Franco PM, Nogueira RL, Souza LAPS. Facilitação neuromuscular proprioceptiva na doença de Parkinson: relato de eficácia terapêutica. Fisioter Mov. 2012;25(2):281-9.

19. Brasil. Ministério da Saúde. Resolução n 466, de 12 de dezembro de 2012. Aprovar diretrizes e normas regulamentadoras de pesquisas envolvendo seres humanos. Diário Oficial da União. 2013 jun. 13. Poder Executivo, Brasília, (DF); 2013. [acesso em 2019 ago 29]. Disponível em: http://bvsms.saude.gov.br/bvs/saudelegis/ cns/2013/res0466_12_12_2012.html

20. Assis CS, Batista LdeC, Wolosker N, Zerati AE, Silva RCG. Medida de independência funcional em pacientes com claudicação intermitente. Rev Esc Enfermagem USP. 2015;49(5):756-61.

\section{Ascari RA, Chapieski CMC, Silva OM, Frigo} J. Perfil Epidemiológico de vítimas de acidente de trânsito. Enfermagem UFSM. 2013 jan./ abr;3(1):112-21.

22. Carvalho ICCM, Saraiva IS. Perfil das vítimas de trauma atendidas pelo serviço de atendimento móvel de urgência, Rev Interd. 2015 jan./ mar;8(1):137-48.

23. Credo PFD, Felix JVC. Perfil dos pacientes atendidos em um hospital de referência ao trauma em Curitiba: implicações para a enfermagem. Cogitare Enfermagem. 2012 jna./ mar;17(1):126-31.

24. Curze J, Junior LAF, Rieder MM. Avaliação da independência funcional após alta da unidade de terapia intensiva. Rev Bras Ter Intensiva. 2013;25(2):93-8.

25. Andrade SM, Moreira KLAF, Oliveira EA, Santos $J B O$, Quirino MAB. Independência funcional e qualidade de vida em pacientes com sequelas neurológicas: a contribuição de um grupo terapêutico interdisciplinar. Ciências \& Cognição. 2010;15(2):155-64.
26. Vasconcelos SS. Perfil epidemiológico e funcional dos Acidentados de trânsito atendidos em um serviço de fisioterapia em fortaleza. [dissertação] Fortaleza: Universidade Federal do Ceara, Faculdade de Medicina. Programa de PósGraduação em Saúde Pública; 2010.

27. Barbosa BR, Almeida JM, Barbosa MR, RossiBarbosa LAS. Avaliação da capacidade funcional dos idosos e fatores associados à incapacidade. Ciênc Saúde Coletiva. 2014;19(8):3317-25.

28. Silva GA, Schoeller SD, Gelbcke FL, Carvalho ZMFC, Silva EMDJdaP. Avaliação Funcional de Pessoas com Lesão Medular: utilização da Escala de Independência Funcional - Mif. Texto Contexto Enfermagem. 2012 out./dez;21(4):929-36.

29. Paiva L, Ross LA, Costa MCS, Dantas RAS. Qualidade de vida na perspectiva de vítimas de Traumas múltiplos e seus familiares. Rev. Enfermagem. UERJ. 2012 out./dez;20(4):507-1.

30. Araújo DC, Pinheiro FGMS, Menezes MGV, Lima SGS, Tavares CSS, Vaez AC. Perfil e fatores associados ao trauma em vítimas de acidentes de trânsito atendidas por serviço móvel de urgência. Arq Ciênc Saúde. 2017 abr./jun;24(2):65-70.

31. Oliveira AF, Oliveira EPRF, Wanginiak TA, Baldo GU. O diabético antes e após uma amputação - Conhecimento sobre pé diabético e consequências das amputações. FisiSenectus. Unochapecó. 2014 jul./dez;2(2):9-18.

32. Caldart J, Faggion M, Santos RV. Eficácia da hidrocinesioterapia na fratura de joelho: estudo de caso. FisiSenectus. Unochapecó. 2013;1(1):63-9.

33. Geiger LSC, Chavaglia SRR, OhI RIB, Barbosa MH, Tavares JL, Oliveira ACD. Trauma por acidentes de trânsito após implantação da Lei n. 11.705 - "Lei Seca". REME - Rev Min Enfermagem. 2018;22:e-1072. 


\section{Anexos}

Figura 1 - Distribuição da categoria autocuidado, Medida de Independência Funcional

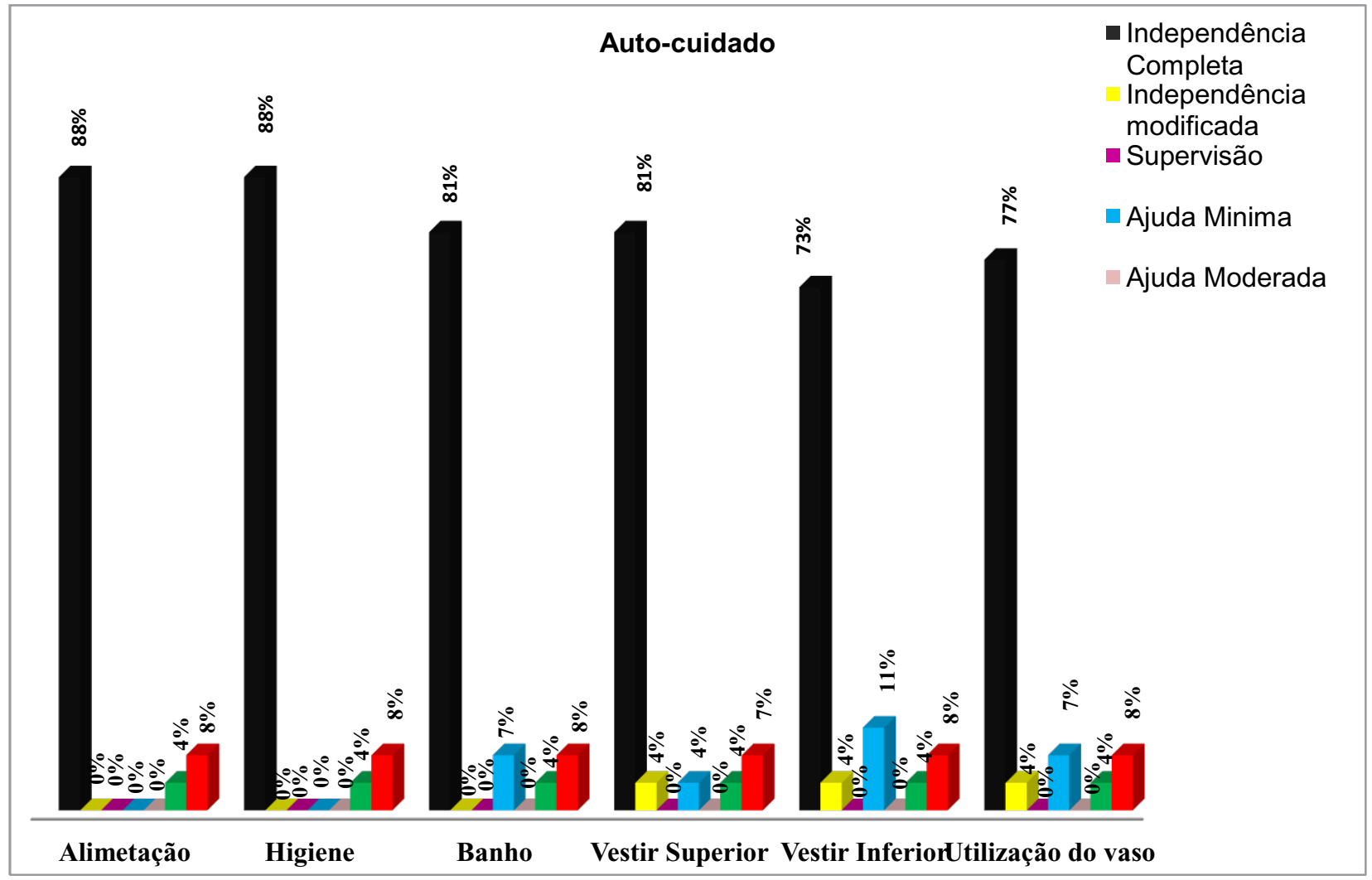

Fonte: Elaborada pelos autores

(clique para voltar ao texto) 
Figura 2 - Distribuição da categoria controle de esfíncteres, Medida de Independência Funcional

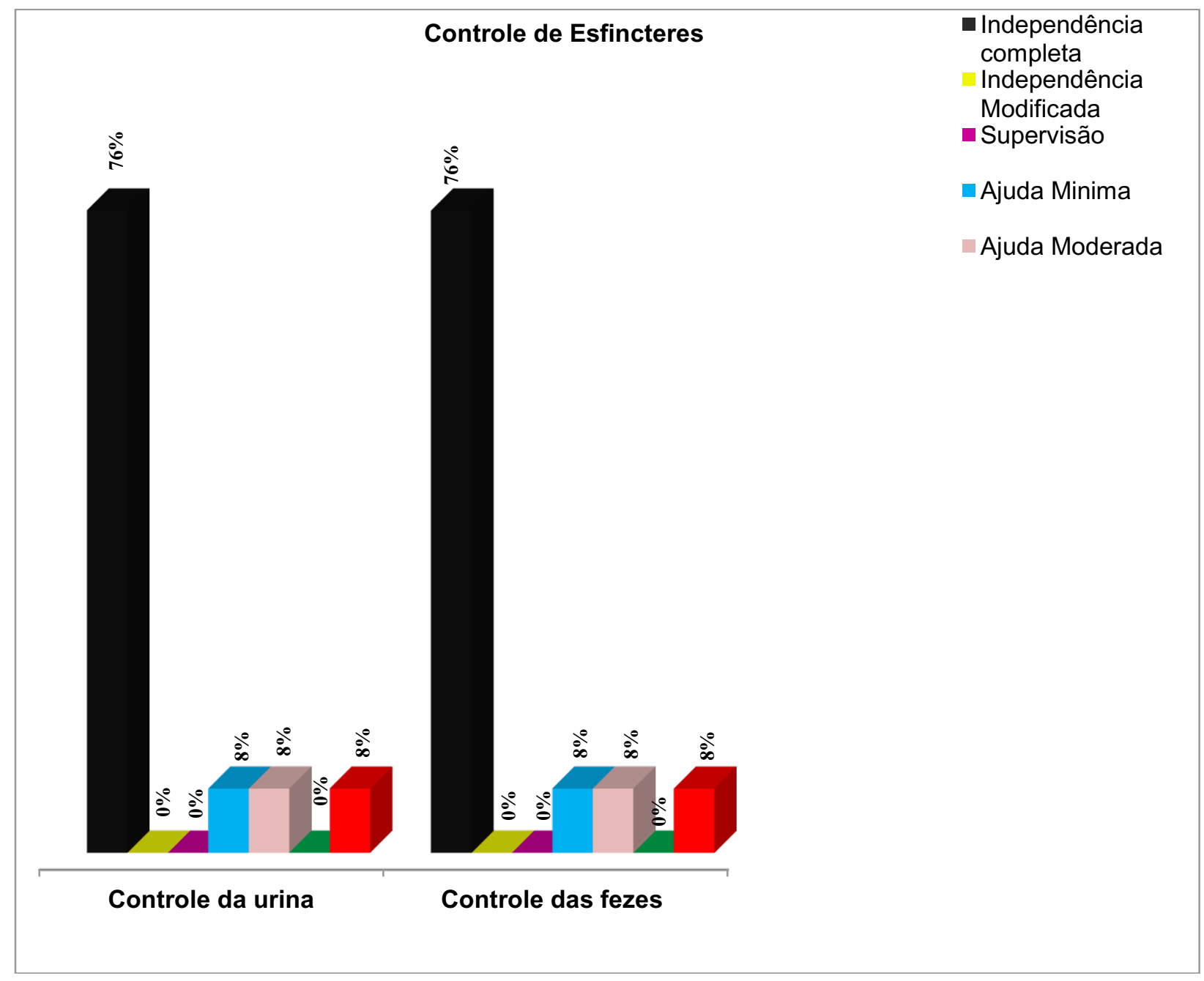

Fonte: Elaborada pelos autores

(clique para voltar ao texto) 
Figura 3 - Distribuição da categoria mobilidade/transferência/ locomoção, Medida de Independência Funcional

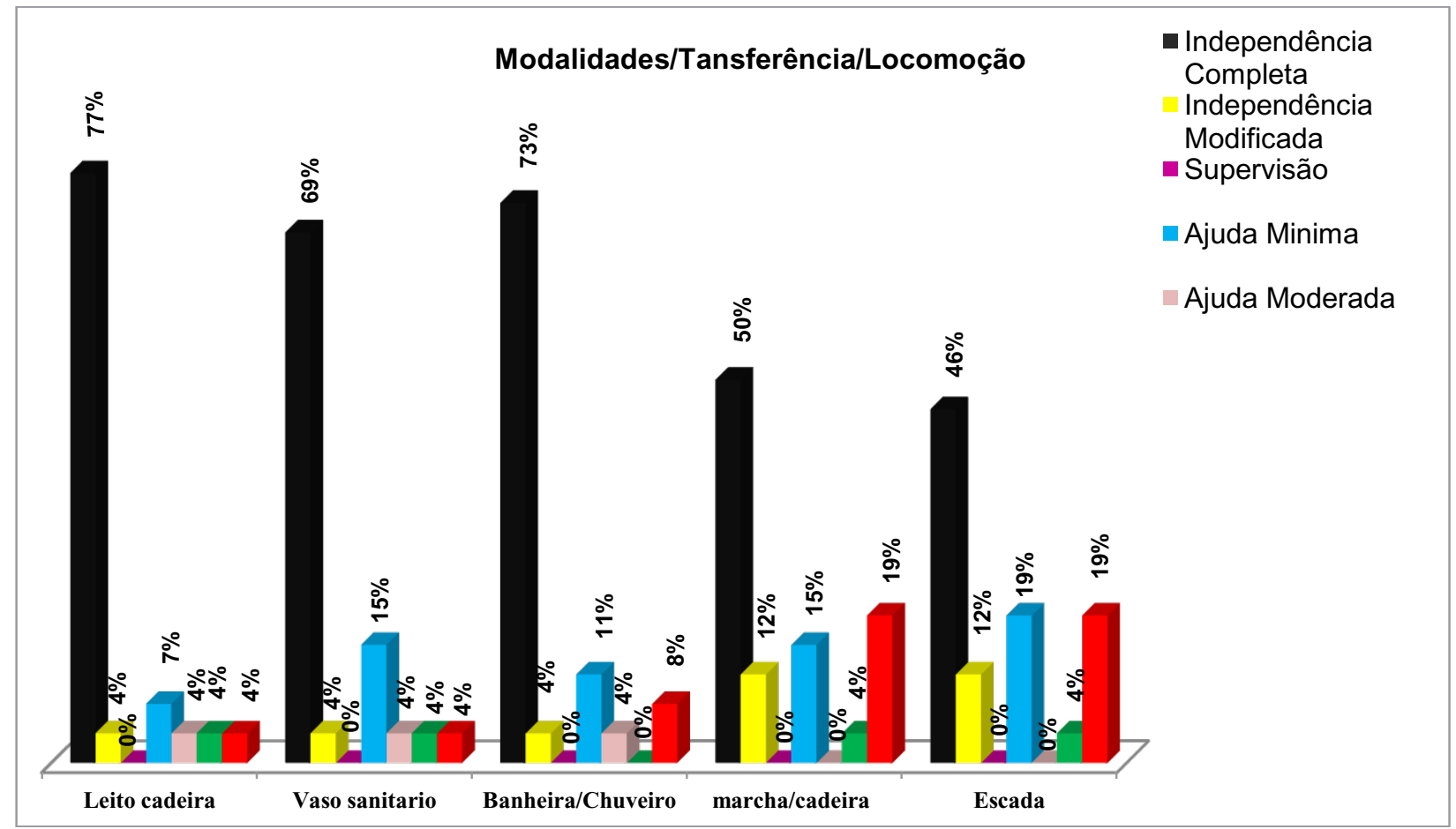

Fonte: Elaborada pelos autores 
Figura 4 - Distribuição de frequência da categoria comunicação/ cognição social, Medida de Independência Funcional

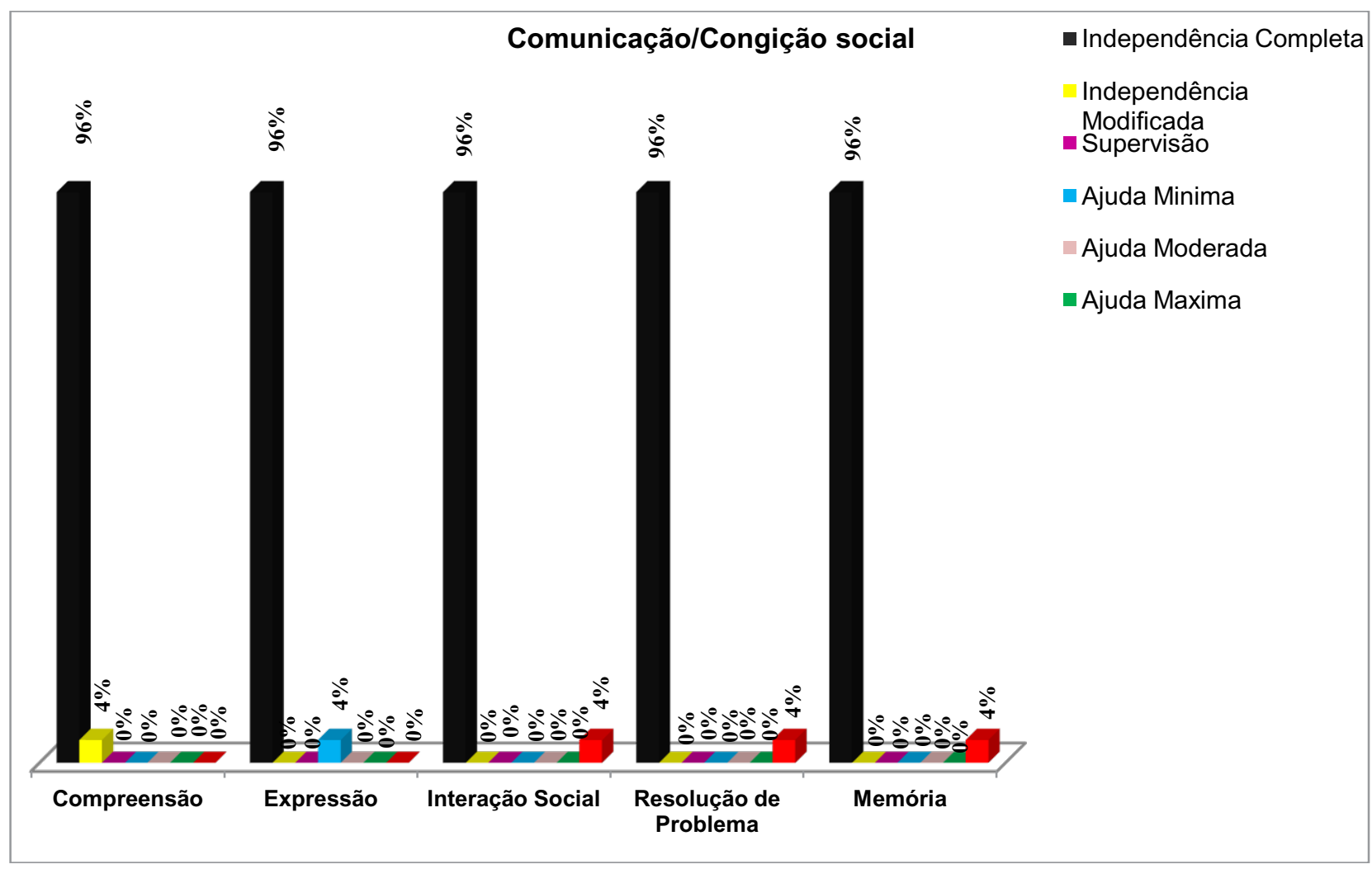

Fonte: Elaborada pelos autores

(clique para voltar ao texto) 
Figura 5 - Distribuição de frequência em relação ao resultado aos escores obtidos na Medida de Independência Funcional

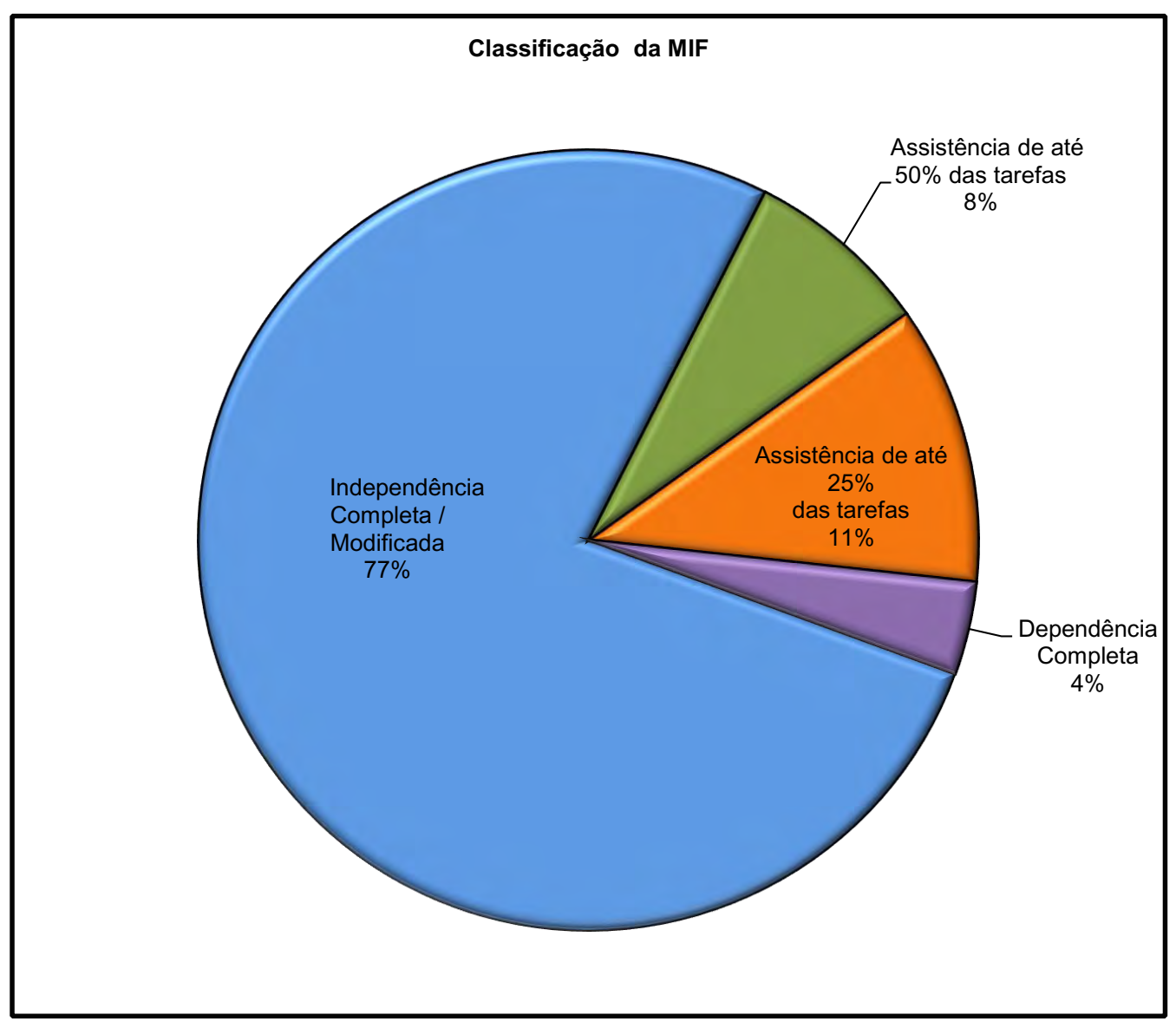

Fonte: Elaborada pelos autores

(clique para voltar ao texto) 